\title{
MAKING TECHNOLOGY HUMAN: REAL TIME INTERACTIONS IN ONLINE LEARNING
}

\author{
Lingma Lu Acheson \\ Indiana University-Purdue University Indianapolis \\ 723 West Michigan Street, SL280, Indianapolis, IN 46202, USA
}

\begin{abstract}
As online education becomes more and more ubiquitous in higher education, instructors are constantly seeking new ways to improve online teaching. Much has been done to increase the effective use of Learning Management Systems and to use student digital footprints to predict learning outcomes, however, prominent teaching strategies such as interpersonal interactions and immediate feedbacks that are common in brick and mortar classrooms are minimized in online learning or replaced by email communications and message board postings. Online education is gradually becoming technology-centered rather than human centered and lack of instructor intervention is still the number one disadvantage of online education. This paper proposes a virtual classroom approach that brings human interactions into online learning. It maximizes the opportunity students can interact with instructor and their peers, and effectively integrates traditional classroom teaching techniques with digital materials. The paper explains how traditional techniques can be adjusted to suit online teaching, and how to help students gain a sense of community, a strong human bond and a rich classroom experience in a virtual learning environment. Course evaluation result shows that student satisfaction rate from the trial class increased significantly over the average of previous semesters.
\end{abstract}

\section{KEYWORDS}

Higher Education, Distant Learning, Real-Time Interaction

\section{PROBLEM STATEMENT}

Online learning has been an integral part of high education across the world. According to BABSON Survey Research Group, distance education student enrollments have increased for the fourteenth straight year in 2016 and 31.6 percent of all students now take at least one distance education course (Seaman J. et al, 2017). More and more brick and mortar universities are increasing their online only degree offerings. Many institutions have adopted an online learning management systems (LMS) such as Blackboard, Angel or WebCT. The purpose of these systems are usually two folds, 1) to effectively distribute and manage learning materials and activities 2) to track participation and progress. With proper instructional design, an LMS can create a learning environment that enables students to take a class $100 \%$ online.

Two most obvious advantages of distance education are flexibility and convenience. The disadvantages of distance education are also clear, such as lack of face to face interaction with the instructor and the huge demand of student self-discipline. The rich array of tools provided by LMS help instructors to gain summary report on student activities, assignment completions and participation records. Because of this, there is a tendency that instructors rely greatly on technology to increase the quality of online education. Many instructors focus on developing better quality teaching materials such as slides or pre-recorded videos, tightly managed discussion items or forums. While all these are highly applauded and should indeed play a great role in online teaching, instructors tend to leave the course running on its own, and limit communication with students to emails or online postings. Online education is starting to lose human touch; however, this human touch is at the heart of the traditional classroom teaching; it is the time when teacher and students laugh together; it is what makes learning interactive and fun. As a matter of fact, many students prefer face-to-face classes than online classes due to "more engagement" and "immediate feedback" (Kemp N. \& Grieve R., 2014). This paper introduces a virtual classroom approach that incorporates human touch into online learning so as to give students a similar experience to the traditional classroom learning while still maintain all the other online learning advantages such as flexibility, low cost and convenience. 


\section{LITERATURE REVIEW}

Researchers have recognized the importance of human interactions in online learning. Moore (1989) identified three types of interactions, i.e. learner-instructor interaction, learner-content interaction and learner-learner interaction. Shackelford and Maxwell (2012) defined seven types of learner-instructor interactions, including providing timely feedback and instructor participating in discussions. A lot of research has been conducted on learner-content interactions, such as which learner-content activities are most effective (Kumtepe, A.T. et al, 2018), the relationship between learner-content interaction and course success (Zimmerman, 2012). For learner-learner interactions, researchers recommend using a variety of groupings, such as whole class and small group discussions, partner assignments, and individual responses (Mayes et al., 2011). Discussions among students, either synchronously or asynchronously, can create a strong sense of community, and can be led either by instructors or students. These three types of interactions can be easily facilitated and integrated in traditional classroom teaching, however, in distance education, much focus lies on promoting each type of interaction rather than the integration of them all. Adding a human touch through digital contents allow an instructor's passion and personality to shine through the online environment, and these practices do have a positive effect on student learning (Conaway T. and Schiefelbein J. 2011), however, much has been done to instill personality into digital materials such as videos, images and email announcements, and these cannot replace the instructor's real time presence in a virtual classroom that mimics the atmosphere of a traditional classroom setting.

\section{APPROACH}

In the proposed approach, instructor meets with students via video conferencing at a fixed time of the week. The video conferencing room serves as the virtual classroom where instructor can conduct a variety of in-class activities such as lecturing, demonstration, facilitating discussions, helping with assignments etc. The software tool selected for this purpose must support audio/video real time group conversations, computer screen sharing, remote desktop control, video recording, private and public chat rooms, small group breakout rooms. These features give instructor different options in designing classroom activities that can best promote interpersonal integrations as well as learner-content integrations. Popular video conferencing software that supports the above features include Web Meeting, Global Meeting Collaboration, Skype and Zoom. The author experimented the virtual classroom approach using Zoom, with a class of 56 students in Fall 2018. Below is a summary of key practices used.

\subsection{Exquisitely Managed Virtual Classroom Sessions}

The class would meet every Monday evening for two hours online. Using Zoom, instructor can create a recurring meeting at the beginning of a semester, and the link for all meetings is the same. Students just need to click on the link to enter the classroom. Clicking on the same link gives the students a feeling of entering the same classroom. Zoom will allow all participants see each other if the student's video camera is on and the participants can talk to one another freely. Once the students are in the virtual classroom, the instructor will orchestrate the class so that this virtual classroom truly functions like a real classroom.

In a physical classroom, the instructor presence ties the class together. Instructor's outlook, mood and personality depict the tone of a class or even an entire course. Same can be said for a virtual classroom. Professional attire, friendly and encouraging voices, carefully selected camera backdrops etc. all contribute to the atmosphere of the classroom. Although the backdrop design should not divert students' attention, changing the backdrop to reflect the current events, holiday or seasonal changes will bring a great deal of human touch to the online class. Props and other objects relevant to teaching materials can be brought into the classroom. Spending some time at the beginning of a semester introducing each other, and later throughout the semester, a minute or two exchanging personal or holiday greetings help to create a strong sense of community and a bond among instructor and students. This course then becomes live to students, and is no longer just some materials to study, videos to watch and assignments to submit. When feeling more connected with each other and with the instructor, students will be more willing to ask questions and seek 
timely help, thus the human touch not only draws student attention to the class but also increases academic performance.

Other learner-centered interactive activities help creating a richer classroom experience as well. Examples include seeking student feedback periodically, asking students to complete a small assignment after watching instructor live demonstrations, and group discussions. Small breakout rooms on Zoom allow students to be separated into different groups, and group activities can be carried out as if they are in a physical classroom. Later, group leaders can report activity outcome to the entire class. Students who feel engaged and connected are more likely to feel satisfied in the learning environment.

In a traditional classroom, the three types of interactions as defined by Moore can be easily integrated. Learner-Instructor and Learner-Learner interaction can be achieved through direct and interpersonal communications inside the classroom. Learner-Content interaction can be done through carefully designed active learning strategies such as Affective Response and Clarification Pauses (Paulson, D. \& Faust J., 2019). Because a virtual classroom can function just like a brick and mortar classroom, instructor can design a class that includes a Q\&A session (Learner-Instructor Interaction), Active Learning activities (Learner-Content Interaction) and student Group Discussions (Learner-Learner Interaction). As a result, instructor intervention and timely feedback which are normally known as common drawbacks in online learning can be fully implemented in a virtual classroom.

\subsection{Adjusted Teaching Strategies to Suit Online Learning}

Due to the nature of online learning, some adjustments must be done in teaching strategies. Instead of using a white board or projector as in a physical classroom, instructor would use his/her own computer screen and share computer screen with students. Lots of video conferencing tools provide this screen sharing capability. As different types of digital materials can be played on a computer, this method is more powerful than using a white board. What's more, each student is looking at instructor's computer screen and hearing instructor's voice at a close distance, as if the instructor is sitting right next to his/her. This makes learner-instructor relationship very personal. Students can also share their screen with each other or with the class, thus makes learner-learner interaction personal.

One of the biggest advantages of online education is the flexibility, which allows students to learn materials at their own pace, or fit school in around their work and family responsibilities. Because of this, attendance to classes should not be required. For those who cannot attend a class, the entire virtual classroom session will be recorded, and the recording will be made available to students within 24 hours. Recording capability is also a standard feature for many video conferencing tools. In the class, instructor can pause and resume recording at any time. Timely release of class recordings is very important so that all students, whether they attend a virtual class or not, are on the same page.

Although attendance is not required, attendance should be taken to encourage student presence in the virtual classroom. In the trial class, the author gave extra credits for students who attend over $90 \%$ of the classes. Another challenge is classroom participation. Students login into the classroom not necessarily mean they are actively listening, thus techniques such as pop-up questions, on-the-fly discussions, and small assignments after demonstrations can be used, and participation records should be kept on track.

Virtual classrooms can be used for instructor or teaching assistant help sessions. All techniques used in the class applies, except that in help sessions, the relationship becomes a one-to-one relationship, rather than a one-to-many relationship. Zoom allows a student to release mouse control to the helper, so that the helper can operate student's computer when necessary. It makes coaching extremely personal and efficient.

\subsection{Well Organized Supporting Materials}

In online education, it is common that abundant digital learning materials are posted in the LMS for self-study. Such materials often include power point slides, text files, and videos. Although virtual classroom sessions play a key role in the class, supplementary learning materials may be posted on LMS as additional resources. The virtual classroom recordings should be logically organized and well mixed with other materials. The role of the virtual classroom should be made clear to students, whether it is the starting point or summary of a topic. Virtual classroom can be the core of the course, or supplementary to other materials, but should not be designed to be the only resource of learning. 


\section{CONCLUSION AND FUTURE WORK}

In the university where author teaches, all students are expected to complete an anonymous end-of-semester online course evaluation. Using the same questionnaire, student satisfaction rate from the trial class showed a significant increase over previous semesters, in the same course taught by the same author. See Figure 1.

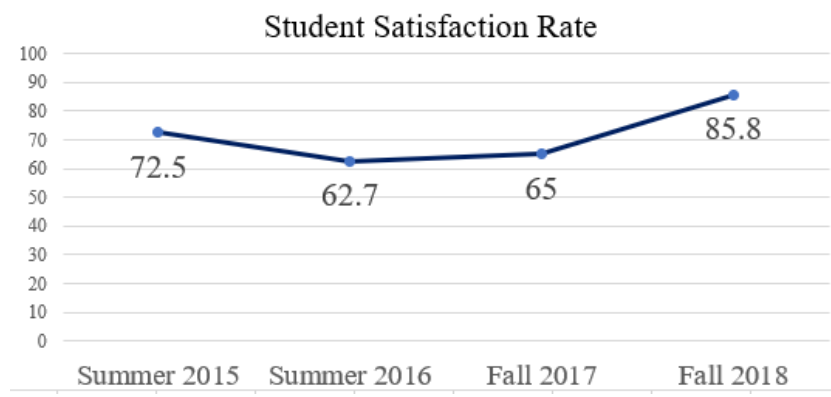

Figure 1. Student satisfaction rate in trial semester (Fall 2018) compared with previous semesters

It is worth a note that national student satisfaction rate in academic year 2014 through 2016 for four-year public institutions was 55\% (Ruffalo Noel Levitz, 2017). While the experiment has gained initial success, there are a few more questions to be answered, such as 1) Will the satisfaction rate remain consistently high in the same class and in other classes? 2) How to handle classes with large enrollments? 3)Should a class be capped under certain enrollment for the virtual classroom approach to be effective? If so, what is that magic number? At the time when this paper is written, the author is conducting a second experiment with a different course and will continue to seek answers for other questions.

\section{REFERENCES}

Conaway, T. \& Schiefelbein, J., 2011, The Human Touch and Your Digital Personality, Online Learning Consortium, Retrieved from https://secure.onlinelearningconsortium.org.

Kemp N. \& Grieve R., 2014, Face-to-face or face-to-screen? Undergraduates' opinions and test performance in classroom vs. online learning, Frontiers in Psychology, 5: 1278, Published online, doi: 10.3389/fpsyg.2014.01278

Kimtepe, A.T. et al, 2018, Effects of Learner-Content Interaction Activities on the Context of Verbal Learning Outcomes in Interactive Courses, Proceedings of Association for Educational Communications \& Technology, Volume 1, Kansas City, USA, pp 104-113.

Moore, M.G. 1989. Three types of interaction. The American Journal of Distance Education, Vol.3, No.2, pp 1-7.

Paulson, D. R. \& Faust, J. L, 2019, Active Learning for the College Classroom, Retrieved from http://www.calstatela.edu/dept/chem/chem2/Active/main.htm.

Ruffalo Noel Levitz (2017). 2017 national student satisfaction and priorities report. Cedar Rapids, Iowa: Ruffalo Noel Levitz. Retrieved from RuffaloNL.com/Benchmark.

Seaman J. et al, 2017. Grade Increase: Tracking Distance Education in the United States. BABSON Survey Research Group, Babson Park, USA.

Shackelford, J. L. \& Maxwell, M., 2012. Contribution of learner to learner interaction to sense of community in graduate online education. Journal of Online Learning and Teaching, Vol.8, No. 4, pp 248-260.

Zimmerman, T. D., 2012, Exploring Learner to Content Interaction as a Success Factor in Online Courses, International Review of Research in Open and Distance Learning, Vol.13, No. 4, pp 152-165. 